\title{
Grand Challenges in Immunological Memory
}

\author{
Scott N. Mueller* \\ Department of Microbiology and Immunology, The University of Melbourne, at the Peter Doherty Institute for Infection and \\ Immunity, Melbourne, Australia
}

Keywords: immunological memory, lymphocytes, MHC tetramers, epigenetics, transcription factors, infection, tissue-resident memory $\mathrm{T}$ cells, human immunology

Immunological memory is a central feature of the immune system that can provide long-lived, specific protection against previously encountered diseases. Despite our increasingly complex understanding of the cellular players, we still do not fully understand the mechanisms underlying immunological memory, and therefore, how best to induce effective memory responses to many infectious diseases.

In the past two decades, significant progress has been made revealing the complexity of lymphocyte populations induced by infections. The use of T-cell receptor transgenic mice in adoptive transfer experiments and major histocompatibility complex tetramer reagents has enabled immunologists to track $\mathrm{T}$ cell responses in mice and humans from the naïve lineage through to memory and during recall of resting memory populations $(1,2)$. This has provided a wealth of information about $\mathrm{T}$ cell specificity, homeostasis, trafficking, and facilitated the definition of multiple subsets of memory $\mathrm{T}$ cells. At least three main subsets of memory $\mathrm{T}$ cells have been defined, including central memory $\left(\mathrm{T}_{\mathrm{CM}}\right)$, effector memory $\left(\mathrm{T}_{\mathrm{EM}}\right)$, and tissue-resident memory $\left(\mathrm{T}_{\mathrm{RM}}\right) \mathrm{T}$ cells (3). Antigen inexperienced CD8 $\mathrm{T}$ cells with a memory phenotype have also been described and may contribute to immunity. As knowledge of $\mathrm{T}$ cell responses has advanced, our understanding of memory $\mathrm{B}$ cell and long-lived plasma cell formation within tissues has come a long way. With the application of B cell receptor transgenic mice and increasingly sophisticated tools to analyze responses in humans, new research is

OPEN ACCESS

Edited and Reviewed by: Luigi Daniele Notarangelo, Harvard Medical School, USA

${ }^{*}$ Correspondence: Scott N. Mueller smue@unimelb.edu.au

Specialty section: This article was submitted to Immunological Memory, a section of the journal

Frontiers in Immunology

Received: 23 February 2017 Accepted: 20 March 2017 Published: 05 April 2017

Citation:

Mueller SN (2017) Grand Challenges in Immunological Memory.

Front. Immunol. 8:385. doi: 10.3389/fimmu.2017.00385 adding to a wealth of information on humoral immunity and memory to pathogens and vaccines (4).

A challenge for the field moving forward will be to better define memory lymphocyte subsets on the basis of function as well as phenotype, the relationships between subsets, and importantly how each correlate with protective immunity. This will be particularly crucial in humans, where $\mathrm{T}$ cell responses are commonly only examined in peripheral blood, whereas memory $\mathrm{T}$ cells, especially $\mathrm{T}_{\mathrm{RM}}$ cells, are highly compartmentalized within non-lymphoid tissues (5). Defining immunological memory in human tissues and determining how to induce circulating and tissue-resident lymphocytes through vaccination is an outstanding challenge for the field.

With technological advancements in intravital imaging and cell tracking, the cellular interactions involved in the activation of $\mathrm{T}$ and $\mathrm{B}$ cells to vaccination and infection are becoming clearer (6). It will be important to better define the cellular interactions in lymphoid and non-lymphoid tissues that underlie the development and homeostasis of memory lymphocyte subsets. Both $\mathrm{T}_{\mathrm{RM}}$ cells and memory lymphocytes that transit from blood to tissues and back again are influenced by tissue microenvironments (7). As such, an important goal should be to define which signals imprint lymphocytes with the ability to develop into different memory subsets and that direct cells to reside in specific tissues and organs. This will be a vital step to combat many diseases, where mucosal, cutaneous, or nervous tissues serve as primary pathogen entry points. In addition, understanding the influence of the microbiome on the formation and maintenance of immunological memory is lacking but could hold substantial promise (8). Recent work highlighting differences between the memory compartments in experimental SPF mice with humans or outbred mice housed under 
non-SPF conditions (pet store mice) also implicate a need to include models of immunological memory that better reflect that in humans (9).

Another area where significant progress continues to be made is in dissection of the molecular pathways required for memory lymphocyte development and function (10). Identification of key transcription factors and transcriptional networks will help in defining how we can better guide memory responses via vaccines and adjuvants. Likewise, how epigenetic modifications are induced and maintained within memory lymphocytes remains to be fully elucidated (11), but advances in the field are making such experiments with small populations of memory cells considerably easier. It will then be critical to determine whether pharmacological interventions to manipulate epigenetic pathways, including DNA methylation and histone acetylation, could provide therapeutic avenues to complement vaccination. In addition to this, we must consider the long-term changes to the metabolism of memory cells that can promote their functions and possibly also persistence (12). Are metabolic changes attuned to tissue microenvironments and can we manipulate this for therapeutic gain?

How memory cells perform immunosurveillance functions and then rapidly respond upon antigen encounter within tissues remains poorly understood and requires further study. Memory $\mathrm{T}$ and $\mathrm{B}$ cell subsets each contribute to protection from reinfection, yet the relative roles of distinct subsets in the context of different infections and tissues are not clear. The ability to analyze single cells at the genomic and proteomic level may prove useful in this regard, as advanced tools to analyze "omics" data and detect differences within phenotypically homogeneous populations become more sophisticated. Also, the fate of memory lymphocytes that are restimulated regularly by pathogens is of particular relevance to human immunology. Such questions have proven extremely challenging, given the difficulty in following populations of memory cells across time and through multiple challenges. At a population level, studies have suggested that the memory compartment can increase in size substantially.

\section{REFERENCES}

1. Altman JD, Moss PA, Goulder PJ, Barouch DH, McHeyzer-Williams MG, Bell JI, et al. Phenotypic analysis of antigen-specific T lymphocytes. Science (1996) 274:94-6. doi:10.1126/science.274.5284.94

2. Kearney ER, Pape KA, Loh DY, Jenkins MK. Visualization of peptide-specific T cell immunity and peripheral tolerance induction in vivo. Immunity (1994) 1:327-39. doi:10.1016/1074-7613(94)90084-1

3. Mueller SN, Gebhardt T, Carbone FR, Heath WR. Memory T cell subsets, migration patterns, and tissue residence. Annu Rev Immunol (2013) 31:137-61. doi:10.1146/annurev-immunol-032712-095954

4. Weisel F, Shlomchik M. Memory B cells of mice and humans. Annu Rev Immunol (2017) 35:255-84. doi:10.1146/annurev-immunol-041015-055531

5. Thome JJ, Yudanin N, Ohmura Y, Kubota M, Grinshpun B, Sathaliyawala $\mathrm{T}$, et al. Spatial map of human $\mathrm{T}$ cell compartmentalization and maintenance over decades of life. Cell (2014) 159:814-28. doi:10.1016/j.cell. 2014.10.026

6. Qi H, Kastenmuller W, Germain RN. Spatiotemporal basis of innate and adaptive immunity in secondary lymphoid tissue. Annu Rev Cell Dev Biol (2014) 30:141-67. doi:10.1146/annurev-cellbio-100913-013254
Tellingly, many human tissues have substantial populations of memory lymphocytes (5). However, the fate of memory cells that are restimulated multiple times is not clear, either at the population or single cell level. Since chronic antigenic stimulation can negatively impact on lymphocyte functions (13), it will be valuable to determine whether memory cells induced by infection or vaccination, which are repeatedly restimulated, retain the ability to quickly and efficiently deal with infections, and if not how we can overcome this.

Another question highly relevant to the field of immunological memory is whether innate immune cells also acquire traits of memory cells after challenge (14). This is established for NK cells that can elicit antigen-specific memory functions in response to viral infection. It is less clear whether other innate lymphoid cell lineages will show similar traits. It is feasible that, like NK cells, many innate cells can be imprinted non-specifically by epigenetic mechanisms to elicit distinct responses upon recall. Whether this constitutes immunological memory will then need to be defined by the field.

The translational challenge that lies ahead is an ability to design new vaccines that can control infections and cancers, within highly diverse human populations. Though we have learnt much about how immune memory populations are formed and can function to protect against disease, the application of this knowledge to many pathogens remains elusive. The recent advances in the field of immunological memory provide plenty of scope for many of these questions to be answered in the near future.

\section{AUTHOR CONTRIBUTIONS}

SM conceived and wrote the article.

\section{FUNDING}

The author is supported by the Australian Research Council (ARC) and the National Health and Medical Research Council (NHMRC) of Australia.

7. Mueller SN, Mackay LK. Tissue-resident memory T cells: local specialists in immune defence. Nat Rev Immunol (2016) 16:79-89. doi:10.1038/nri.2015.3

8. Honda K, Littman DR. The microbiota in adaptive immune homeostasis and disease. Nature (2016) 535:75-84. doi:10.1038/nature18848

9. Beura LK, Hamilton SE, Bi K, Schenkel JM, Odumade OA, Casey KA, et al. Normalizing the environment recapitulates adult human immune traits in laboratory mice. Nature (2016) 532:512-6. doi:10.1038/nature17655

10. Chang JT, Wherry EJ, Goldrath AW. Molecular regulation of effector and memory T cell differentiation. Nat Immunol (2014) 15:1104-15. doi:10.1038/ ni.3031

11. Russ BE, Prier JE, Rao S, Turner SJ. T cell immunity as a tool for studying epigenetic regulation of cellular differentiation. Front Genet (2013) 4:218. doi:10.3389/fgene.2013.00218

12. Buck MD, O'Sullivan D, Pearce EL. T cell metabolism drives immunity. J Exp Med (2015) 212:1345-60. doi:10.1084/jem.20151159

13. Attanasio J, Wherry EJ. Costimulatory and coinhibitory receptor pathways in infectious disease. Immunity (2016) 44:1052-68. doi:10.1016/ j.immuni.2016.04.022

14. Netea MG, Joosten LA, Latz E, Mills KH, Natoli G, Stunnenberg HG, et al. Trained immunity: a program of innate immune memory in 
health and disease. Science (2016) 352:aaf1098. doi:10.1126/science. aaf1098

Conflict of Interest Statement: The author declares that the research was conducted in the absence of any commercial or financial relationships that could be construed as a potential conflict of interest.
Copyright $\odot 2017$ Mueller. This is an open-access article distributed under the terms of the Creative Commons Attribution License (CC BY). The use, distribution or reproduction in other forums is permitted, provided the original author(s) or licensor are credited and that the original publication in this journal is cited, in accordance with accepted academic practice. No use, distribution or reproduction is permitted which does not comply with these terms. 